\title{
Diagnostic re-evaluation of congenital hypothyroidism in Macedonia: predictors for transient or permanent hypothyroidism
}

\author{
Nikolina Zdraveska', Maja Zdravkovska², Violeta Anastasovska', Elena Sukarova-Angelovska' and \\ Mirjana Kocova'
}

${ }^{1}$ University Children's Hospital Skopje, Faculty of Medicine, Skopje, Republic of Macedonia

${ }^{2}$ Institute of Patophysiology and Nuclear Medicine, Faculty of Medicine, Skopje, Republic of Macedonia

Correspondence should be addressed to M Kocova: mirjanakocova@yahoo.com

\begin{abstract}
Background: Diagnostic re-evaluation is important for all patients with congenital hypothyroidism $(\mathrm{CH})$ for determining the etiology and identifying transient $\mathrm{CH}$ cases. Our study is a first thyroxine therapy withdrawal study conducted in Macedonian $\mathrm{CH}$ patients for a diagnostic re-evaluation. We aimed to evaluate the etiology of $\mathrm{CH}$, the prevalence of transient $\mathrm{CH}$ and identify predictive factors for distinguishing between permanent $(\mathrm{PCH})$ and transient $\mathrm{CH}(\mathrm{TCH})$.

Materials and methods: Patients with $\mathrm{CH}$ aged $>3$ years underwent a trial of treatment withdrawal for 4 weeks period. Thyroid function testing (TFT), ultrasound and Technetium- $99 \mathrm{~m}$ pertechnetate thyroid scan were performed thereafter. TCH was defined when TFT remained within normal limits for at least 6-month follow-up. PCH was diagnosed when TFT was abnormal and classified according the imaging findings. Results: 42 (55\%) patients had $\mathrm{PCH}$ and 34 (45.0\%) patients had TCH. Thyroid agenesia was the most prevalent form in the $\mathrm{PCH}$ group. Patients with $\mathrm{TCH}$ had lower initial thyroid-stimulating hormone $(\mathrm{TSH})$ values $(P<0.0001)$; higher serum thyroxine levels $(P=0.0023)$ and lower mean doses of levothyroxine during treatment period $(P<0.0001)$ than patients with $\mathrm{PCH}$. Initial TSH level $<30.5 \mathrm{IU} / \mathrm{mL}$ and levothyroxine dose at 3 years of age $<2.6 \mathrm{mg} / \mathrm{kg} / \mathrm{day}$ were a significant predictive factors for $\mathrm{TCH}$; sensitivity $92 \%$ and $100 \%$, specificity $75.6 \%$ and $76 \%$, respectively.

Conclusion: TCH presents a significant portion of patients with $\mathrm{CH}$. Initial TSH value and levothyroxine dose during treatment period has a predictive role in differentiating $\mathrm{TCH}$ from $\mathrm{PCH}$. Earlier re-evaluation, between 2 and 3 years age might be considered in some patients requiring low doses of levothyroxine.
\end{abstract}

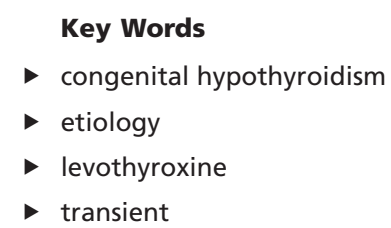

Endocrine Connections (2018) 7, 278-285

\section{Introduction}

Thyroid hormones play important role in the processes of neuronal migration and differentiation, myelination and synaptogenesis and are essential for proper neurodevelopment (1). Congenital hypothyroidism $(\mathrm{CH})$ is generally classified into two main groups: permanent $\mathrm{CH}$ and transient $\mathrm{CH}$ depending on the lifelong therapy requirements. The vast majority of $\mathrm{CH}$ children will have permanent hypothyroidism: thyroid dysgenesis (TD) due to abnormal thyroid development or thyroid dyshormonogenesis due to defects of thyroid hormone biosynthesis. The etiologic evaluation of $\mathrm{CH}$ is possible through several examinations, such as ultrasonography,
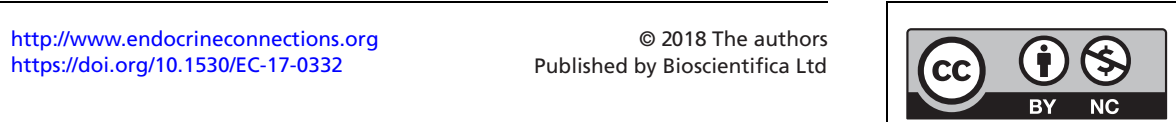

This work is licensed under a Creative Commons Attribution-NonCommercial 4.0 International License. 
scintigraphy, thyroglobulin measurement and perchlorate discharge test. There are also cases where the results can be inconclusive even after performing several diagnostic tests. The etiology of $\mathrm{CH}$ is important for determining the severity of the disease and its prognosis, clinical management and the need for genetic counseling. A number of recent studies worldwide have reported a change in the epidemiology of $\mathrm{CH}$ with a doubling incidence of 1 in 1500 live newborns, mostly caused by the increasing number of the mild and potentially transient $\mathrm{CH}$ cases with eutopic thyroid gland $(2,3)$.

Long-term follow-up of $\mathrm{CH}$ cases is of particular interest in the last decade. Although unfavorable outcome of untreated $\mathrm{CH}$ is well established, recent evidence suggests that many $\mathrm{CH}$ children are no longer treated after the age of 3 years $(4,5,6)$.

To distinguish between transient and permanent forms, the guidelines recommend re-evaluation after 3 years of age in all children with unexplained $\mathrm{CH}$ through a trial of treatment withdrawal. This is important since some cases of transient $\mathrm{CH}$ caused by identifiable or non-identifiable factors may require only a short-term therapy $(7,8)$.

Here, we report the results of the first thyroxine therapy withdrawal study conducted in Macedonia through a diagnostic re-evaluation following a standardized protocol. We aimed to evaluate the etiology of $\mathrm{CH}$ and determine the prevalence of transient hypothyroidism among $\mathrm{CH}$ children diagnosed in the newborn period after the neonatal screening.

Neonatal screening for $\mathrm{CH}$ in the Republic of Macedonia was introduced in 2002 as a pilot project and since 2007 , it is mandatory in the entire country.

\section{Materials and methods}

\section{Patients}

Patients detected through the neonatal screening in the period April 2002-December 2015 are included. A total of 251,008 newborns were screened with a mean coverage of the $96.7 \%$. The overall incidence of primary $\mathrm{CH}$ was $1 / 1967$ and female-to-male ratio was 1.35:1 $(9,10)$. Children with $\mathrm{CH}$ detected by neonatal screening program were followed at a single center of the University Children's Hospital. The neonatal screening was carried out by determination of whole-blood thyroid-stimulating hormone (TSH) on dried blood spot specimen obtained from newborns 48 to $72 \mathrm{~h}$ after birth by fluoroimmunometric DELFIA assay.

$$
\begin{array}{lr}
\text { http://www.endocrineconnections.org } & \text { (อ) } 2018 \text { The authors } \\
\text { https://doi.org/10.1530/EC-17-0332 } & \text { Published by Bioscientifica Ltd }
\end{array}
$$

The TSH cut-off level was 15 IU/L in the period 2002-2010 and $10 \mathrm{IU} / \mathrm{L}$ thereafter. Preterm or sick newborns were screened between the first and second week of life. Birth weight, gestational age and time of sampling were recorded on the blood spot card for adequate interpretation. Results between 10 and $15 \mathrm{IU} / \mathrm{L}$ were considered borderline and repeat analysis (new blood spot card) was requested usually 7 days after the previous test. Whenever the repeated blood sampling TSH concentration was higher than $10 \mathrm{IU} / \mathrm{L}$, patients were recalled for biochemical and clinical evaluation. The diagnosis of $\mathrm{CH}$ was based on the abnormal thyroid function tests (TSH $>10$ IU/L and low or normal $\mathrm{T}_{4}$ or $\mathrm{FT}_{4}$ ) on confirmatory serum measurements.

\section{Study design}

All children diagnosed with $\mathrm{CH}$ were immediately initiated on levothyroxine $\left(\mathrm{LT}_{4}\right)$ treatment. The patients underwent regular thyroid function tests (TFT), as well as assessment of growth and development, mainly at 3 -month intervals. Children aged $\geq 3$ years underwent trial off therapy for period of 4 weeks and were scheduled for re-evaluation thereafter. Parents were advised to monitor for signs and symptoms of hypothyroidism. After four weeks off therapy clinical assessment, TFT and imaging studies were performed.

Children with abnormal TFT were classified as having permanent hypothyroidism (PCH), thus, $\mathrm{LT}_{4}$ therapy was restarted at previous dose and titrated thereafter. Further classification of $\mathrm{PCH}$ was based on the ultrasound and scintigraphy findings (athyreosis, thyroid ectopia, hypoplasia or probable dyshormonogeneis). Probable dyshormonogenesis was defined when a large thyroid gland in the eutopic position with increased uptake was found on imaging studies. Children in whom TFT, ultrasound and scintigraphy were normal were followed with serial TFT tests every month for at least 6-month period. If the TFT remained normal, they were classified as transient hypothyroidism (TCH). Patients in whom the therapy was stopped between 2 and 3 years of age during the regular follow-up because of continuously normal TFT or low thyroxine dose underwent thyroid re-testing and ultrasonography. If the results were within normal limits, they were diagnosed as $\mathrm{TCH}$, and no further follow-up was recommended.

\section{Laboratory and imaging methods}

TSH and $\mathrm{T}_{4} / \mathrm{FT}_{4}$ were measured using IMMULITE 2000 chemiluminescent enzyme immunoassay system (Siemens

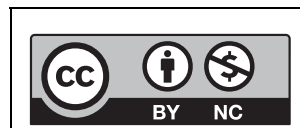

This work is licensed under a Creative Commons Attribution-NonCommercial 4.0 International License. 
Healthcare Diagnostics Inc.). Values of thyroid hormones ranging from the 3rd to the 97th percentile standardized for age were considered normal (11). Reference values: $\mathrm{T}_{4}$ : 4.5-10.9 $\mu \mathrm{g} / \mathrm{dL}, \mathrm{FT}_{4}: 0.9-1.8 \mathrm{ng} / \mathrm{dL}, \mathrm{TSH}$ 0.4-5.0 IU/L.

Thyroid ultrasound (SonoScape SSI-5000 Color Doppler Ultrasound System, SonoScape Medical Corp., Shenzhen, China) was performed to detect the presence of the thyroid gland and assess the size and echostructure. The size of thyroid gland was determined by measurement of the volume of the thyroid lobes and their comparison with the reference values from the literature (12). Thyroid scan was performed by double-head Mediso gamma camera after an intravenous injection of $99 \mathrm{~m}$-technetium pertechnetate $(2 \mathrm{MBq} / \mathrm{kg})$ and obtaining standard anterior and lateral images in supine position. The presence, size and location of areas of $99 \mathrm{mTcO} 4$ uptake were recorded.

\section{Data analysis}

Statistical analysis was performed using the SPSS for Windows statistical package (version 17.0). The following variables were analyzed: gestational age, sex, birthweight, initial values of $\mathrm{TSH}$ and $\mathrm{T}_{4}$, age at treatment initiation, initial $\mathrm{LT}_{4}$ dose, $\mathrm{LT}_{4}$ dose at 1, 2 and 3 years of age and at re-evaluation. Comparison between the two groups for numerical variables was performed with the Student's t-test and the Mann-Whitney test. Pearson's chisquare test was used in the comparison of proportions. One-way ANOVA analysis followed by post hoc Tukey HSD (honestly significant difference) test was used for comparison between the etiological subgroups of patients with permanent hypothyroidism.

Logistic regression analysis was used to investigate predictors for transient $\mathrm{CH}$. Several parameters that showed significant difference between $\mathrm{TCH}$ and $\mathrm{PCH}$ groups were applied in the ROC (receiver-operating characteristic) analysis. The optimal cut-off point of each predictor was determined, and sensitivity and specificity were calculated for this cut-off value. For comparison of ROC curves, MedCalc for Windows (version 17.8, MedCalc Software, Ostend, Belgium) was used. $P$ values lower than 0.05 were considered statistically significant.

\section{Ethical approval}

All procedures performed in study were in accordance with the ethical standards of the Helsinki Medical Declaration and its later amendments. The study protocol was approved by Medical Faculty's Ethical Committee,

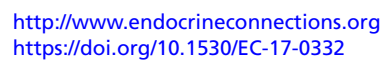

and informed consent was obtained from the parents of the children included in the study.

\section{Results}

A total of 127 neonates detected by national neonatal thyroid screening were confirmed to have primary $\mathrm{CH}$, in the period 2002-2015, with an overall incidence of 1:1967 live births. Thirty-seven children were excluded from the present study because of age less than 3 years and 14 children because of incomplete medical records, lost from follow-up, parents' refusal or Down syndrome. Therapy was interrupted in $55 \mathrm{CH}$ children for mean period of 30 days (range 28-40 days). All patients were clinically euthyroid on levothyroxine therapy at the time of enrollment. The mean age was $6.5 \pm 2.8$ years (range: $3-13$ years); 35 were girls and 20 were boys. In $21 \mathrm{CH}$ children treatment was discontinued during the regular follow-up at mean age of $25.4 \pm 4.7$ months (range: 18-33 months). Forty-two patients $(55 \%)$ were classified in the $\mathrm{PCH}$ group and 34 (45\%) in TCH group based on the defined criteria. The prevalence of $\mathrm{PCH}$ was $1 / 3586$ and the prevalence of $\mathrm{TCH}$ was $1 / 4404$. Figure 1 shows the flow diagram of the study. The ratio of sex was not significantly different between $\mathrm{TCH}$ and $\mathrm{PCH}$ groups $(P=0.091)$. Treatment for $\mathrm{CH}$ was initiated at a mean age of $12.1( \pm 4.1)$ days, and it was not significantly different between the groups (Table 1). Patients in the TCH group exhibited significantly lower TSH levels compared to subjects in the $\mathrm{PCH}$ group (Table 1). The initial levothyroxine doses, as well as $\mathrm{LT}_{4}$ dose at 1, 2 and 3 years of age were significantly lower in TCH subjects (Table 1 ).

Thyroid agenesia was the most prevalent cause of permanent hypothyroidism present in one half of the patients $(n=21)$, followed by thyroid ectopy $(n=13)$, hypoplasia $(n=4)$ and probable thyroid dyshormonogenesis in the other 4 cases (Table 2). Among the patients with ectopic thyroid gland (10 females and 3 males), two and five patients had submental and lingual thyroid gland, respectively, and the remaining six patients had sublingual uptake on scintigraphy.

A significant difference in the TSH and $\mathrm{T}_{4}$ values at diagnosis and after treatment discontinuation was also observed in children with $\mathrm{PCH}$ subdivided in different etiological groups: athyreosis, ectopy, hypoplasia and dyshormonogenesis, $P<0.05$ (Table 2). Patients with thyroid agenesia had significantly higher TSH values at diagnosis compared to patients with ectopy, hypoplasia and putative dyshormonogenesis. After 4 weeks off 


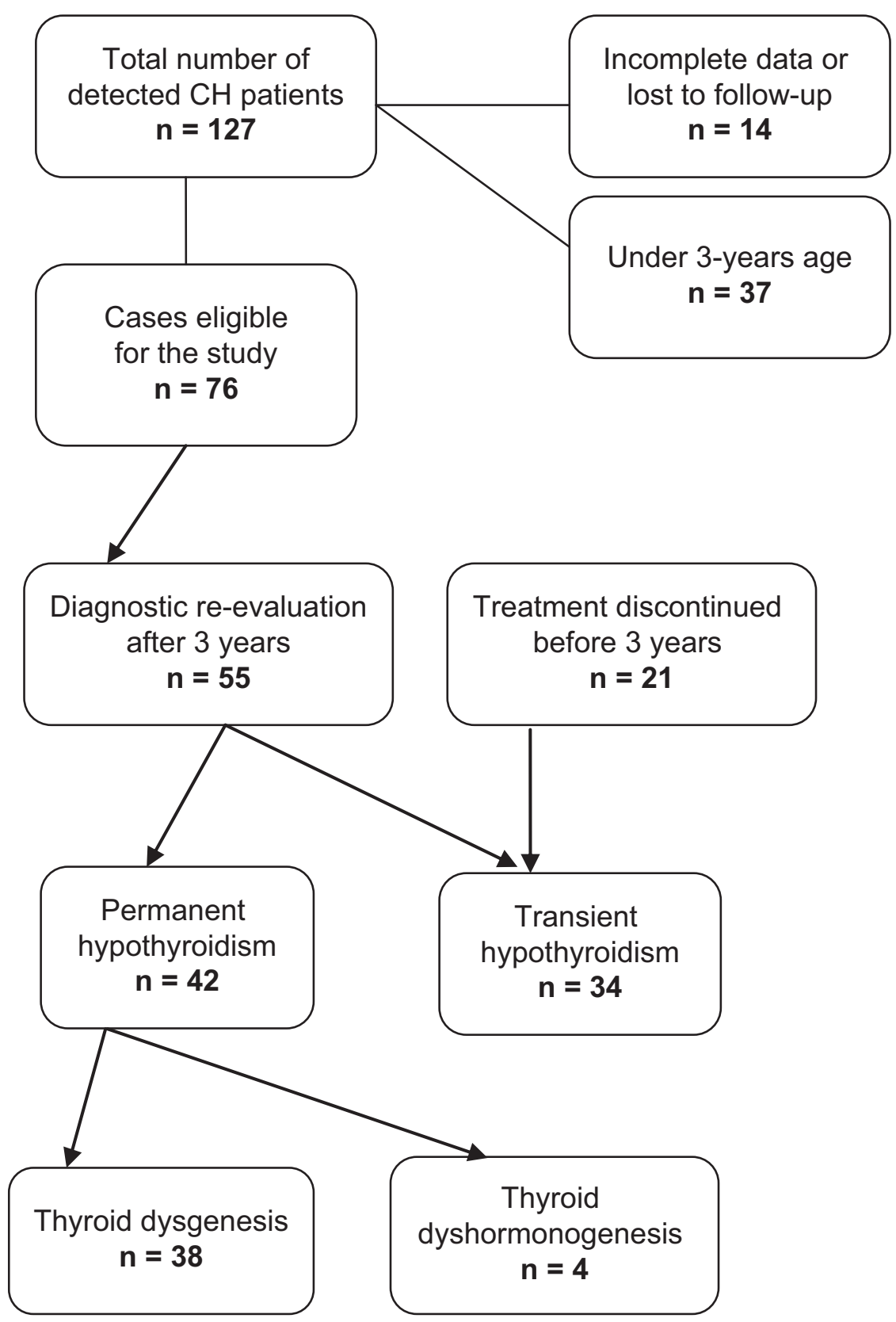

Figure 1

Flow diagram of the follow-up study.

therapy, TSH values did not significantly differ between athyreosis and ectopies $(P=0.427)$. The results of the Tukey HDS post hoc test indicating differences within $\mathrm{PCH}$ subgroups are presented in Table 3.

\section{Predictive factors suggesting transient congenital hypothyroidism}

According to the ROC curve analysis, initial TSH value $<30.5 \mathrm{IU} / \mathrm{mL}$ was associated with $\mathrm{TCH}$, showing $92 \%$ sensitivity and $75.6 \%$ specificity, with an area under the ROC curve (AUC) $0.850(P<0.001)$. Also initial serum $\mathrm{T}_{4}$
$>3.6 \mu \mathrm{g} / \mathrm{dL}$ was associated with TCH with $92 \%$ sensitivity and $63.4 \%$ specificity, AUC $0.778(P<0.001)$.

The optimal cut-off points for the $\mathrm{LT}_{4}$ dose during treatment as a predictor for distinguishing $\mathrm{PCH}$ and $\mathrm{TCH}$ were as follows: initial $\mathrm{LT}_{4}$ dose $11.0 \mu \mathrm{g} / \mathrm{kg} / \mathrm{day}$, with $96 \%$ sensitivity and $70.7 \%$ specificity, AUC 0.857; $\mathrm{LT}_{4}$ dose at 1 year of age $3.0 \mu \mathrm{g} / \mathrm{kg} /$ day, $86.4 \%$ sensitivity and $76.5 \%$ specificity, AUC 0.880; $\mathrm{LT}_{4}$ dose at 2 years of age $2.8 \mu \mathrm{g} / \mathrm{kg} / \mathrm{day}, 95.2 \%$ sensitivity and $82.6 \%$ specificity, AUC 0.904; $\mathrm{LT}_{4}$ dose at 3 years of age $2.6 \mu \mathrm{g} / \mathrm{kg} / \mathrm{day}, 100 \%$ sensitivity and $76 \%$ specificity, AUC 0.921. In a logistic regression analysis with an initial $\mathrm{TSH}$ and $\mathrm{T}_{4}$ levels,

$$
\begin{array}{lr}
\text { http://www.endocrineconnections.org } & \text { @ } 2018 \text { The authors } \\
\text { https://doi.org/10.1530/EC-17-0332 } & \text { Published by Bioscientifica Ltd }
\end{array}
$$


Table 1 Comparison of the clinical and laboratory characteristics of patients with congenital hypothyroidism.

\begin{tabular}{|c|c|c|c|}
\hline Total $(n=76)$ & $\begin{array}{l}\text { Permanent } \\
\text { CH }(n=42)\end{array}$ & $\begin{array}{l}\text { Transient } \\
\text { CH }(n=34)\end{array}$ & $P$ value \\
\hline \multicolumn{4}{|l|}{$\operatorname{Sex}(N)$} \\
\hline Female & 29 & 17 & $0.091^{a}$ \\
\hline Male & 13 & 17 & \\
\hline Birth weight (kg) & $3.4 \pm 0.5$ & $3.1 \pm 0.6$ & 0.303 \\
\hline Gestational age (week) & $39.3 \pm 1.2$ & $38.9 \pm 1.6$ & 0.121 \\
\hline $\begin{array}{l}\text { Age of treatment } \\
\text { initiation (day) }\end{array}$ & $11.3 \pm 4.2$ & $13.8 \pm 3.4$ & 0.076 \\
\hline \multicolumn{4}{|l|}{ Thyroid tests at diagnosis } \\
\hline TSH ( $\mu \mathrm{IU} / \mathrm{L})$ & $81.9 \pm 56.8$ & $22.7 \pm 10.9$ & $<0.0001$ \\
\hline$T_{4}(\mu g / d L)$ & $4.8 \pm 3.9$ & $6.7 \pm 2.4$ & 0.0023 \\
\hline \multicolumn{4}{|c|}{ Levothyroxine dose $(\mu \mathrm{g} / \mathrm{kg})$} \\
\hline Initial & $11.8 \pm 2.1$ & $9.2 \pm 1.5$ & 0.002 \\
\hline 1 year & $3.7 \pm 0.8$ & $2.4 \pm 0.7$ & $<0.0001$ \\
\hline 2 years & $3.3 \pm 0.7$ & $\begin{array}{l}1.9 \pm 0.6 \\
(N=30)\end{array}$ & $<0.0001$ \\
\hline 3 years & $3.2 \pm 0.7$ & $\begin{array}{l}1.7 \pm 0.6 \\
(N=14)\end{array}$ & $<0.0001$ \\
\hline At re-evaluation & $2.6 \pm 0.6$ & $\begin{array}{l}1.4 \pm 0.5 \\
(N=13)\end{array}$ & \\
\hline
\end{tabular}

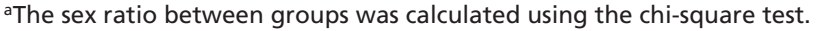

and the levothyroxine dose during the treatment period as independent variables, the initial TSH levels and the levothyroxine dose at 3 years of age were significant predictors of a TCH diagnosis (Fig. 2 and Table 4).

\section{Discussion}

Early detection and attainment of euthyroid status as quickly as possible are essential for all children with primary $\mathrm{CH}$ for achieving an optimal neurodevelopment. Another significant point in addition to early treatment is specification of underlying cause of $\mathrm{CH}$, thus identifying transient cases and preventing overtreatment. The results of our study showed that almost $45 \%$ of patients diagnosed with $\mathrm{CH}$ through neonatal screening had transient $\mathrm{CH}$ and do not require lifelong thyroid hormone supplementation. Although the prevalence of transient $\mathrm{CH}$ varies in different studies an increasing trend has been observed worldwide in the recent years $(5,6,13$, $14,15,16)$. One possible explanation for this increased incidence is the change in screening strategies, such as lowering the TSH cut-off values that allows more sensitive detection and early intervention. The TSH cut-off was lowered in our national thyroid screening program from 15 to $10 \mathrm{IU} / \mathrm{L}$ after 2010. The overall incidence of $\mathrm{CH}$ significantly increased from $1 / 2489$ up to 2010 to $1 / 1585$ thereafter, with increasing the prevalence of transient $\mathrm{CH}$ cases (10). However, the optimal cut-off in this study was $30.5 \mathrm{IU} / \mathrm{L}$. Kang and coworkers reported a similar TSH cut-off point of $31 \mathrm{IU} / \mathrm{L}$ for distinguishing TCH and $\mathrm{PCH}$ (17). Other studies suggested initial TSH cut-off values of $28.4 \mathrm{IU} / \mathrm{L}$ and $34 \mathrm{IU} / \mathrm{L}(14,18)$. Generally, it is safe to refer to the current guidelines, which suggest an immediate treatment if $\mathrm{TSH}>20 \mathrm{IU} / \mathrm{L}$ and clinicians individual approach for cases with TSH values between $6 \mathrm{IU} / \mathrm{L}$ and 20IU/L (7). Prematurity is often reported to be associated with TCH $(19,20)$. In our study, there was no significant difference in the birth weight and the duration of gestation between the $\mathrm{TCH}$ and $\mathrm{PCH}$ group. Other factors that might have contributed to TCH are ethnic modifications in the population, variations in iodine supply, endocrinedisrupting chemicals exposure etc. (3). A recently published study accessing the iodine status through TSH measurements on newborn screening reported iodine sufficiency in Macedonia (21). Considering these facts the etiology of the most of our TCH cases remains unknown.

Table 2 Characteristics of patients with permanent congenital hypothyroidism.

\begin{tabular}{|c|c|c|c|c|c|}
\hline \multicolumn{6}{|c|}{ Permanent CH $(n=42)$} \\
\hline & \multicolumn{3}{|c|}{ Thyroid dysgenesis $(n=38)$} & \multicolumn{2}{|c|}{ Thyroid dyshormonogenesis $(n=4)$} \\
\hline Etiology & Athyreosis $(n=21)$ & Ectopy $(n=13)$ & Hypoplasia $(n=4)$ & & $P$ \\
\hline \multicolumn{6}{|l|}{ Thyroid function tests } \\
\hline \multicolumn{6}{|l|}{ At time of diagnosis } \\
\hline $\mathrm{TSH}(\mu \mathrm{IU} / \mathrm{L})$ & $122.5 \pm 51.2$ & $67.1 \pm 40.7$ & $31.3 \pm 17.3$ & $30.9 \pm 18.7$ & $<0.05^{*}$ \\
\hline $\mathrm{T}_{4}(\mu \mathrm{g} / \mathrm{dL})$ & $2.9 \pm 2.7$ & $6.4 \pm 4.2$ & $7.3 \pm 4.6$ & $6.8 \pm 3.1$ & $<0.05^{*}$ \\
\hline \multicolumn{6}{|c|}{ After treatment discontinuation } \\
\hline TSH $(\mu \mathrm{IU} / \mathrm{L})$ & $72.2 \pm 10.6$ & $58.8 \pm 27.1$ & $35.9 \pm 21.8$ & $27.3 \pm 10.6$ & $<0.05^{*}$ \\
\hline $\mathrm{T}_{4}(\mu \mathrm{g} / \mathrm{dL})$ & $1.1 \pm 0.1$ & $3.6 \pm 2.8$ & $6.8 \pm 3.5$ & $3.2 \pm 3.0$ & $<0.05^{*}$ \\
\hline \multicolumn{6}{|l|}{ L-Thyroxine dose } \\
\hline At time of diagnosis & $12.2 \pm 2.2$ & $11.5 \pm 1.1$ & $10.9 \pm 2.8$ & $10.3 \pm 2.0$ & 0.256 \\
\hline $\begin{array}{l}\text { At time of treatment } \\
\text { discontinuation }\end{array}$ & $2.6 \pm 0.5$ & $2.9 \pm 0.8$ & $2.3 \pm 0.9$ & $2.37 \pm 0.4$ & 0.237 \\
\hline
\end{tabular}

*The $P$ value corresponding to the $\mathrm{F}$ statistic of one-way ANOVA for the initial TSH values and TSH at re-evaluation is lower than 0.05 suggesting for significant difference between the $\mathrm{CH}$ etiology groups.

$$
\begin{aligned}
& \text { http://www.endocrineconnections.org } \\
& \text { https://doi.org/10.1530/EC-17-0332 }
\end{aligned}
$$


Table 3 Tukey HDS ('Honestly Significant Difference') post hoc test results indicating which groups significantly differ from others providing $95 \%$ confidence interval.

\begin{tabular}{|c|c|c|c|c|}
\hline & \multicolumn{2}{|c|}{ At diagnosis } & \multicolumn{2}{|c|}{ After treatment discontinuation } \\
\hline & Tukey HSD Q statistic & $P$ value & Tukey HSD Q statistic & $P$ value \\
\hline \multicolumn{5}{|l|}{ TSH value } \\
\hline Athyreosis vs ectopy & 4.9351 & $0.0066 * *$ & 2.1721 & 0.4272 \\
\hline Athyreosis vs hypoplasia & 5.7550 & $0.0013 * *$ & 6.8050 & $0.0010 * *$ \\
\hline Athyreosis vs dyshormonogenesis & 5.9677 & $0.0010 * *$ & 8.4170 & $0.0010 * *$ \\
\hline Ectopy vs hypoplasia & 2.0516 & 0.4923 & 4.7093 & $0.0094 * *$ \\
\hline Ectopy vs dyshormonogenesis & 2.2164 & 0.4106 & 6.1942 & $0.0010 * *$ \\
\hline Hypoplasia vs dyshormonogenesis & 0.1690 & 0.8999 & 1.2859 & 0.7772 \\
\hline \multicolumn{5}{|l|}{$\mathrm{T}_{4}$ value } \\
\hline Athyreosis vs ectopy & 3.995 & $0.035 * *$ & 4.5641 & $0.0126 * *$ \\
\hline Athyreosis vs hypoplasia & 4.378 & $0.018 * *$ & 8.0208 & $0.0010 * *$ \\
\hline Athyreosis vs dyshormonogenesis & 3.047 & 0.153 & 2.9966 & 0.1643 \\
\hline Ectopy vs hypoplasia & 1.058 & 0.866 & 4.1226 & $0.0282 * *$ \\
\hline Ectopy vs dyshormonogenesis & 0.035 & 0.899 & 0.5289 & 0.8999 \\
\hline Hypoplasia vs dyshormonogenesis & 0.923 & 0.899 & 4.0283 & $0.0332 * *$ \\
\hline
\end{tabular}

Patients with TCH exhibited significantly lower TSH and higher $\mathrm{T}_{4}$ levels at the time of diagnosis compared to those with $\mathrm{PCH}$. Some previous studies in the literature reported that the initial $\mathrm{T}_{4}$ did not differentiate between $\mathrm{TCH}$ and PCH cases $(13,17,22)$.

Forty-two children had permanent hypothyroidism after re-evaluation, and thyroid agenesia was the most prevalent etiology. Thyroid dyshormonogenesis was suspected in 4 patients with $\mathrm{PCH}$ based on the thyroid volume ultrasound and abnormal scintigraphy uptake. However, definitive diagnosis of dyshormonogenesis requires a perchlorate discharge test or a molecular genetic analysis and unfortunately neither of them was available in our center. The initial TSH and $\mathrm{T}_{4}$ values were significantly different between the $\mathrm{PCH}$ subgroups, which corresponds to the reports from other studies in the literature $(23,24)$.

Another interesting finding in our study was the difference in the initial TSH values between patients with athyreosis and thyroid ectopy, which was not observed after trial off therapy. This might be due to the titration of the levothyroxine dose during the follow-up in patients with thyroid ectopy. Thus, the similar clinical course and therapy requirement of both athyreosis and ectopies is obvious. The levothyroxine dose was not significantly different between the $\mathrm{PCH}$ subgroups at initiation and at re-evaluation period.

However, the initial $\mathrm{LT}_{4}$ dose was significantly different between patients with transitory and permanent hypothyroidism. The current guidelines recommend starting dose of $10-15 \mu \mathrm{g} / \mathrm{kg} /$ day, but considering the heterogeneity of $\mathrm{CH}$, some children may require smaller doses because of some endogenous thyroid hormone production. Since imaging studies were not performed in all of our patients at diagnosis, the initial dose was mainly based on the results of TFT. However, targeted $\mathrm{LT}_{4}$ dosing based on the laboratory and thyroid anatomy might be reasonable in some prospective study in the future.

During the treatment period, significant dose differences were observed between the patients with $\mathrm{PCH}$

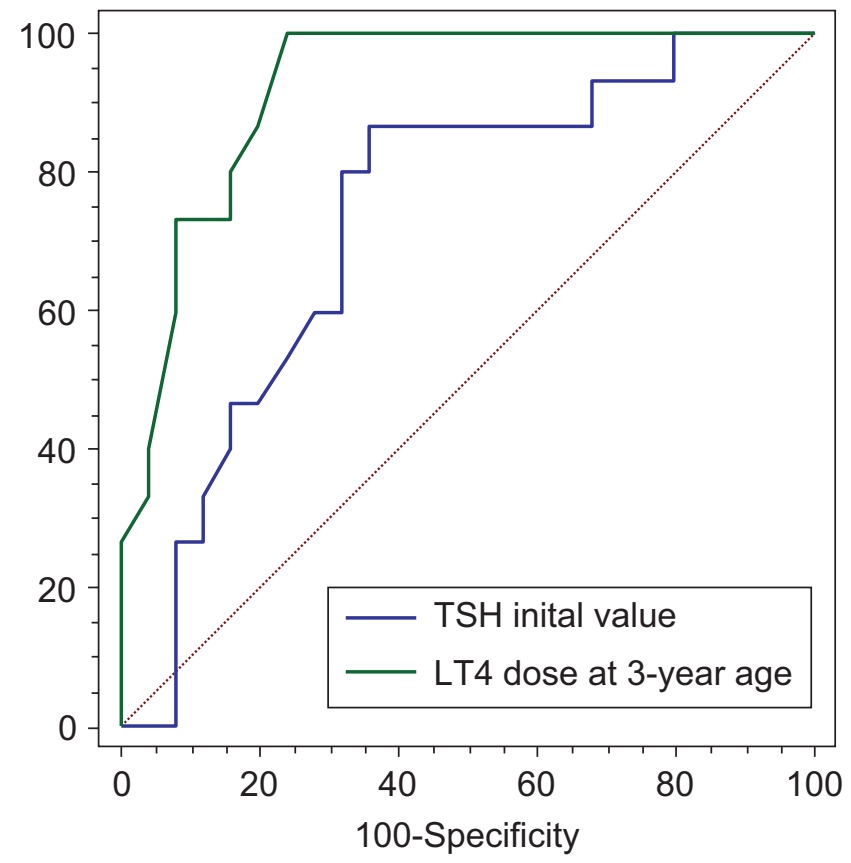

Figure 2

ROC curves shows both the initial TSH values and the levothyroxine dose at 3 years of age were predictive factors for discrimination between transient and permanent congenital hypothyroidism. 
Table 4 Logistic regression analysis of factors associated with transitory congenital hypothyroidism.

\begin{tabular}{lll}
\hline Predictors & & Coefficient \\
\cline { 1 - 2 } Initial TSH value & & 2.3069 \\
Initial $\mathrm{T}_{4}$ value & & -0.004274 \\
Initial $\mathrm{LT}_{4}$ dose & & -0.003676 \\
$\mathrm{LT}_{4}$ dose at 1-year age & -0.08351 \\
$\mathrm{LT}_{4}$ dose at 2-year age & -0.1185 \\
$\mathrm{LT}_{4}$ dose at 3-year age & -0.2374
\end{tabular}

$* P<0.05$

and TCH $(3.7 \mu \mathrm{g} / \mathrm{kg} / \mathrm{day}$ vs $2.4 \mu \mathrm{g} / \mathrm{kg} /$ day at 12 months and $3.3 \mu \mathrm{g} / \mathrm{kg} /$ day vs $1.9 \mu \mathrm{g} / \mathrm{kg} /$ day at 24 months). Moreover, the levothyroxine dose at 3-year age was a positive predictor of $\mathrm{TCH}$ diagnosis. Many authors emphasize the $\mathrm{LT}_{4}$ dose as a discriminate factor between TCH and $\mathrm{PCH}$. Messina and coworkers reported that $\mathrm{LT}_{4}$ requirements $>4.9 \mu \mathrm{g} / \mathrm{kg} /$ day at 12 months age or $>4.27 \mu \mathrm{g} / \mathrm{kg} /$ day at 24 months were highly suggestive of $\mathrm{PCH}$, irrespective of gland ultrasonography (22).

Cho and coworkers reported that children requiring $\mathrm{LT}_{4}$ dose lower than $3.25 \mu \mathrm{g} / \mathrm{kg} /$ day at 12 and 24 months were likely to have $\mathrm{TCH}$, suggesting that earlier re-evaluation is possible in these patients (between 12 and 24 months rather than after 3 years) (18). A significant proportion of patients with $\mathrm{TCH}$ in our study had discontinued treatment within 36 months and confirmed to have a transient hypothyroidism thereafter. Thus, the re-evaluation through one-month trial off therapy might be considered at 2 years of age in patients requiring low doses of $\mathrm{LT}_{4}$ during follow-up. In our study, a levothyroxine dose of $2.6 \mu \mathrm{g} / \mathrm{kg}$ at 3 years of age might be used to predict the diagnosis of $\mathrm{TCH}$.

Our study presents a first diagnostic re-evaluation of Macedonian children with $\mathrm{CH}$ following a standardized protocol. However, it has several limitations. The small number of cases and unavailability of genetic analysis for the diagnosis of dyshormonogenesis are some of them. Extension of the study in the future with the newly diagnosed $\mathrm{CH}$ children, as well as the longer follow-up period of cases with transient hypothyroidism is warranted.

In conclusion, $45 \%$ of cases diagnosed with $\mathrm{CH}$ had of a transient form of hypothyroidism. Patients with TCH had lower initial TSH levels and higher initial $\mathrm{T}_{4}$ values, as well as lower levothyroxine dose requirements during the follow-up than PCH patients. A levothyroxine dose lower than $2.6 \mu \mathrm{g} / \mathrm{kg} /$ day at 3 years of age might predict $\mathrm{TCH}$. Although inconsistent to the current guidelines, earlier re-evaluation of children younger than 3 years might be
Std. error

0.001965

0.01800

0.02828

0.06334

0.06672

0.07304

\begin{tabular}{l}
\multicolumn{1}{c}{$\boldsymbol{r}_{\text {partial }}$} \\
\hline-0.3691 \\
-0.03725 \\
-0.2705 \\
-0.2315 \\
-0.3085 \\
-0.5104
\end{tabular}

\begin{tabular}{c}
\hline $\boldsymbol{t}$ \\
\hline-2.175 \\
-0.204 \\
-1.539 \\
-1.304 \\
-1.776 \\
-3.251
\end{tabular}

$P$ value

0.0376 *

0.8396

0.1343

0.2023

0.0858

0.0028 *

safe in patients requiring low doses of $\mathrm{LT}_{4}$, thus preventing unnecessary or excessive treatment of TCH.

\section{Declaration of interest}

All authors declare no conflict of interest that could be perceived as prejudicing the impartiality of the research reported.

\section{Funding}

This research did not receive any specific grant from any funding agency in the public, commercial or not-for-profit sector.

\section{References}

1 Horn S \& Heuer H. Thyroid hormone action during brain development: more questions than answers. Molecular and Cellular Endocrinology 2010315 19-26. (https://doi.org/10.1016/j. mce.2009.09.008)

2 Harris KB \& Pass KA. Increase in congenital hypothyroidism in New York State and in the United States. Molecular Genetics and Metabolism 200791 268-277. (https://doi.org/10.1016/j.ymgme.2007.03.012)

3 Persani L. Congenital hypothyroidism with gland in situ is more frequent than previously thought. Frontiers in Endocrinology 20123 18. (https://doi.org/10.3389/fendo.2012.00018)

4 Gruters A, Jenner A \& Krude H. Long-term consequences of congenital hypothyroidism in the era of screening programmes. Best Practice and Research: Clinical Endocrinology and Metabolism 200216 369-382. (https://doi.org/10.1053/beem.2002.0202)

5 Kemper AR, Ouyang LJ \& Grosse SD. Discontinuation of thyroid hormone treatment among children in the United States with congenital hypothyroidism: findings from health insurance claims data. BMC Pediatrics 201010 9. (https://doi.org/10.1186/14712431-10-9)

6 Eugster EA, LeMay D, Zerin JM \& Pescovitz OH. Definitive diagnosis in children with congenital hypothyroidism. Journal of Pediatrics 2004144 643-647. (https://doi.org/10.1016/j.jpeds.2004.02.020)

7 Leger J, Olivieri A, Donaldson M, Torresani T, Krude H, van Vliet G, Polak M, Butler G, ESPE-PES-SLEP-JSPE-APEG-APPESISPAE, Congenital Hypothyroidism Consensus Conference Group et al. European Society for Paediatric Endocrinology consensus guidelines on screening, diagnosis, and management of congenital hypothyroidism. Journal of Clinical Endocrinology and Metabolism 2014 99 363-384. (https://doi.org/10.1210/jc.2013-1891)

8 American Academy of Pediatrics, Rose SR, Section on Endocrinology and Committee on Genetics, American Thyroid Association, Brown RS, Public Health Committee, Lawson Wilkins Pediatric Endocrine Society, Foley T, Kaplowitz PB, Kaye CI, et al. Update of newborn screening and therapy for congenital hypothyroidism.

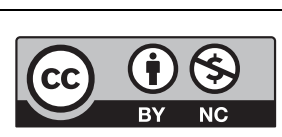

This work is licensed under a Creative Commons Attribution-NonCommercial 4.0 International License. 
Pediatrics 2006117 2290-2303. (https://doi.org/10.1542/peds.20060915)

9 Kocova M, Anastasovska V, Sukarova-Angelovska E, Tanaskoska M $\&$ Taseva E. Clinical practice: experience with newborn screening for congenital hypothyroidism in the Republic of Macedonia - a multiethnic country. European Journal of Pediatrics 2015174 443-448. (https://doi.org/10.1007/s00431-014-2413-4)

10 Anastasovska A \& Kocova M. Impact of lower screening TSH cutoff level on the increasing prevalence of congenital hypothyroidism. International Journal of Neonatal Screening 20173 007. (https://doi. org/10.3390/ijns3020007)

11 Kapelari K, Kirchlechner C, Hogler W, Schweitzer K, Virgolini I \& Moncayo R. Pediatric reference intervals for thyroid hormone levels from birth to adulthood: a retrospective study. BMC Endocrine Disorders 20088 15. (https://doi.org/10.1186/14726823-8-15)

12 Chanoine JP, Toppe V, Lagasse R, Spehl M \& Delange F. Determination of thyroid volume by ultrasound from the neonatal period to late adolescence. European Journal of Pediatrics 1991150 395-399. (https://doi.org/10.1007/BF02093716)

13 Rabbiosi S, Vigone MC, Cortinovis F, Zamproni I, Fugazzola L, Persani L, Corbetta C, Chiumello G \& Weber G. Congenital hypothyroidism with eutopic thyroid gland: analysis of clinical and biochemical features at diagnosis and after re-evaluation. Journal of Clinical Endocrinology and Metabolism 201398 1395-1402. (https:// doi.org/10.1210/jc.2012-3174)

14 Lim HK, Kim KH, Kim SH, No HY, Kim CJ, Woo YJ \& Hwang TJ. Predictors of transient hypothyroidism in neonatal screening test. Journal of Korean Society of Pediatric Endocrinology 200611 50-56.

15 Unuvar T, Demir K, Abacı A, Buyukgebiz A \& Bober E. The role of initial clinical and laboratory findings in infants with hyperthyrotropinemia to predict transient or permanent hypothyroidism. Journal of Clinical Research in Pediatric Endocrinology 20135 170-173. (https://doi.org/10.4274/Jcrpe.931)

16 Korzeniewski SJ, Grigorescu V, Kleyn M, Young WI, Birbeck G, Todem D, Romero R \& Paneth N. Transient hypothyroidism at 3-year follow-up among cases of congenital hypothyroidism detected by newborn screening. Journal of Pediatrics 2013162 177-182. (https:// doi.org/10.1016/j.jpeds.2012.06.050)

17 Kang MJ, Chung HR, Oh YJ, Shim YS \& Hwang IT. Three-year follow-up of children with abnormal newborn screening results for congenital hypothyroidism. Pediatrics and Neonatology 201758 442-448. (https://doi.org/10.1016/j.pedneo.2017.01.002)

18 Cho MS, Cho GS, Park SH, Jung MH, Suh BK \& Koh DG. Earlier reevaluation may be possible in pediatric patients with eutopic congenital hypothyroidism requiring lower L-thyroxine doses. Annals of Pediatric Endocrinology and Metabolism 201419 141-145. (https://doi.org/10.6065/apem.2014.19.3.141)

19 Corbetta C, Weber G, Cortinovis F, Calebiro D, Passoni A, Vigone MC, Beck-Peccoz P, Chiumello G \& Persani L. A 7-year experience with low blood TSH cutoff levels for neonatal screening reveals an unsuspected frequency of congenital hypothyroidism (CH). Clinical Endocrinology 200971 739-745. (https://doi.org/10.1111/j.1365-2265.2009.03568.x)

20 Radetti G, Fanolla A, Pappalardo L \& Gottardi E. Prematurity may be a risk factor for thyroid dysfunction in childhood. Journal of Clinical Endocrinology and Metabolism 200792 155-159. (https://doi. org/10.1210/jc.2006-1219)

21 Anastasovska V \& Kocova M. Newborn screening for thyroidstimulating hormone as an indicator for assessment of iodine status in the Republic of Macedonia. Journal of Medical Biochemistry 201635 385-389. (https://doi.org/10.1515/jomb-2016-0023)

22 Messina MF, Aversa T, Salzano G, Zirilli G, Sferlazzas C, De Luca F \& Lombardo F. Early discrimination between transient and permanent congenital hypothyroidism in children with eutopic gland. Hormone Research in Paediatrics 201584 159-164. (https://doi. org/10.1159/000435811)

23 Dias VM, Campos AP, Chagas AJ \& Silva RM. Congenital hypothyroidism: etiology. Journal of Pediatric Endocrinology and Metabolism 201023 815-826. (https://doi.org/10.1515/jpem.2010.131)

24 Perry RJ, Maroo S, Maclennan AC, Jones JH \& Donaldson MDC. Combined ultrasound and isotope scanning is more informative in the diagnosis of congenital hypothyroidism than single scanning. Archives of Disease in Childhood 200691 972-976. (https://doi. org/10.1136/adc.2006.096776)

Received in final form 10 January 2018

Accepted 15 January 2018

Accepted Preprint published online 15 January 2018 http://www.endocrineconnections.org https://doi.org/10.1530/EC-17-0332 (c) 2018 The authors Published by Bioscientifica Ltd

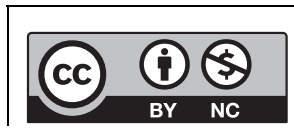

This work is licensed under a Creative Commons Attribution-NonCommercial 4.0 International License. 